\title{
The Analysis of Color Teaching for Chinese Painting Major in Academy of Arts and Design of Tsinghua University
}

\author{
Runqing Cao \\ Academy of Arts and Design \\ Tsinghua University \\ Beijing, China
}

\begin{abstract}
Modern Chinese painting teaching system is affected by the western ones, which leads to the necessity of Chinese painting teaching to absorb the advantages of other disciplines on the basis of traditional methods in order to be practical and effective, and then more talents could be trained to inherit and innovate Chinese painting. Combining color and ink is one of the trends in development of modern Chinese painting. Chinese painting major of Tsinghua Academy of Arts and Design was established not long ago, while under the guidance of the teaching concepts of its former department Central Arts and Crafts Academy, the teaching method of emphasizing color perceptions is formed. Besides, academy professors' works also reveal extremely abundant color expressive forces.
\end{abstract}

Keywords-Chinese painting teaching; color; Central Arts and Crafts Academy; Tsinghua Academy of Arts and Design

\section{INTRODUCTION}

The integration and development of eastern and western art has become an important theme since the 20th century, and traditional Chinese art education has also been combined with the western teaching system to some extent. In the context of an increasingly diverse art form developing era, Tsinghua Academy of Arts and Design combines eastern and western traditions and new art trends, and concentrates on the traditional advantage of design major to accomplish a more comprehensive discipline establishment, thus it formed the Chinese painting major. In line with the trend of combining color and ink in Chinese painting and a scientific color view, the Academy focuses on cultivating color perception of students.

\section{The Double Cultural EXPERIEnCES OF Modern CHINESE PAINTERS}

In the course of its development, Traditional Chinese painting approaches its perfectness and produced numerous masterpieces, which makes it an independent exist among the art of the world. Undoubtedly, because of this glory, huge burdens are leaved to future generations, which caused its disadvantage of lack of energy or conventionally imitating predecessors. In the late Ming and early Qing dynasty the trend of Western learning spread to the East, and process of
Chinese society development began to be influenced and the concept of science began to spread in China.

In the 19th century, western impressionism revealed the possibilities of a colorful world, and at home, it set off a wave of learning from the west and blending the east and the west. Creating an art with an epical character became the pursuit of some artists. Around 1920, many young students studied abroad in France, Japan or others. And they brought a new education model called sketch and color into art teaching when they came back. The development of Chinese painting and the expression are affected, while the influence has both its pros and cons, the author merely focuses on the beneficial influence of color teaching on Chinese painting education.

There is no doubt that since the western teaching system is utilized in China, most Chinese painter gain more solid basic skills than Chinese painters of any time before. They are deeply realized painting should be a visual expression of art, rather than the expression of literature, psychology or philosophy. Chinese painters gradually establish the sense of colors through a long-term color guidance and color viewing as well as trainings on their ways of thinking. Their use of color casts off the yoke of the natural color and image and enables scientific color perception from color itself. In his thesis Situation and Trend of Contemporary Chinese Painting, Mr Lang Shaojun specifically summarized several main ways of Chinese painting creation, and he pointed out that color change is an important one in Chinese painting. The color and ink combination is the current stage development and innovation trend of Chinese painting. Problems stand ahead are how to grasp the degree of combination and how to absorb the advantage of other subjects on the basis of traditional culture.

\section{Transition In Teaching Methods AcCORDingly}

Drawing class was included in curriculum in $1902 . \mathrm{Li}$ Shutong, returning from Japan after his further study, once taught in Hangzhou. He promoted that reform of the traditional Chinese painting should refer to the Tokyo art school curriculum design which includes painting and art history courses. In 1914, Liu Haisu brought the painting 
classes with life models to his own class (in Shanghai Academy of Fine Arts, which also became one of the development centers of Chinese western painting art before the First World War). New culture movement lit the enthusiasm of young people, during which around 1920, France became young artist's dream land. Xu Beihong came to Paris and then entered National Academy of Fine Arts in Paris (école Nationale Supérieure des Beaux-arts de Paris), in which a small minority of Chinese students the national minority Chinese students are qualified. He believed sketch training as a basic skill in painting is necessary, and he brought it down with him as the standard of art education in the future career. Change in basic education Chinese painting has changed the traditional learning mode of Chinese painters conventionalize their paintings, and western scientific sketch and color education have become the basis for Chinese painters.

Chromatics subsequently entered China's art education and almost all painters were influenced by it after the 1950s. Chinese painters began to pay more attention to the expressiveness of color. Understanding of color is gradually deepening, and color is no longer simply a natural existence in real scene, but a kind of visual symbol with changes in temperature, space and emotion in art creation.

Through a long-term guiding, viewing and thinking pattern training toward colors, of the and looked, Chinese painters gradually establish the sense to color, and their use of color casts off the yoke of the natural color and image and they apply scientific color perception from color itself.

\section{Two PERIOds of TSINGHUA ACADEMY OF ART AND DESIGN DEVELOPMENT}

The Central Academy of Arts and Crafts was established in 1956, and it joined Tsinghua University in 1999 and was renamed Tsinghua Academy of Art and Design. At the beginning of its establishment, the college aims to cultivate talents specialize on a combination of artistic creation, design, process production and production skills, and they are expected to provide all-round services to the society. Central Academy of Arts and Crafts focuses on traditional research as well as modern art, and the tradition of design has established here after the founding of new China.

The traditional advantages of the Academy(Central Academy of Arts and Crafts) was decoration and design, and professors, such as PangXunqin, Zheng Ke, Lei Guiyuan, Zhang Ding and others, all have multiple identities as cartoonist, pattern designer, print artist, oil painter, and traditional Chinese painters. Mr Zhang Guangyu once said he did not want to be called a cartoonist or a print artist because he wanted to keep himself open to all the other art forms that he was interested in rather than get caught in a single form of art. Under the leadership of these gentlemen, the Academy emphasizes not only craftsmanship, but design, training of art cultivation and painting foundation. Teaching is categorized into different stages. The first stage is basic painting courses, and then arts and crafts lessons. Many students majored in Arts and Crafts have gained outstanding achievements in painting and other artistic creation fields, thanks to the open and comprehensive teaching ideas.

On November 20th, 1999, the Academy formally merged into Tsinghua University, representing the Academy goes from art design into a wider field of art, and a more comprehensive discipline system was carried out. Design is not just used to serve the people, still it should bear aesthetic value. Solid basic designing capabilities and a great aesthetic vision determines the student's work, and also determines the future of the student and the vitality of development. In December 1999, the Basic Department and Decoration Art Department were revoked, and Department of Painting, Sculpture and Craft art was established. In 2002, Basic Teaching Research Office was established with subordinates include sketch teaching and research group, color teaching and research group, fine brushwork and detail painting teaching and research group, print painting teaching and research group. All the above organizations undertake basic course teaching tasks of undergraduate bachelor's courses in the Academy of Arts.1 As a comprehensive school of higher education with a complete set of domestic specialties and superior teaching conditions, Tsinghua Academy of Art and Design has 10 departments and 25 majors. The Academy pays attention to all aspects of development of students. As for its credit system, $5 \%$ of the courses is free choice courses, $12 \%$ elective courses of the Art Academy, and the rests are compulsory course, including major compulsory courses and art theory, foreign language, politics, Chinese, sports, etc. It can be seen from the credit allocation that the goal of teaching is to let the students make full use of school resources to develop their own interests and combine them with their major after fully studying the skills, technology and art accomplishment, which draws a clear line between the Academy and those art academies whose teaching ideas are emphasizing students' skill training.

\section{COLOR TEACHING CONCEPT OF CHINESE PAINTING IN TSINGHUA ACADEMY OF ART AND DESIGN}

Tsinghua University is the one of the most demanding universities in China that it has higher demands for students' learning ability and literature cultivation. After entering the undergraduate sessions, students begin to learn their own specialized courses, before which they take part in the training of model pattern and design foundation.

Undergraduate students of Chinese national painting major are not necessarily received professional education of Chinese painting before entering college, and they only start to take up traditional Chinese realistic painting and freehand brushwork in traditional Chinese painting after entering the second year. The training plan of Tsinghua Academy of Art and Design of undergraduate program can be concluded through the table below. Students of Chinese National Painting major take elective courses like composition, color sketch etc. besides Chinese painting courses. Tsinghua

A Brief History of the Academy of Art and Design of Tsinghua University, chief editor Hang Jian, and compiled by the Academy history editorial committee, Tsinghua University Press. On page 159 of the 2011 edition. 
Academy of Art offers students traditional design, color composition classes and other elective courses of designing major, and this enables students lay a good foundation for drawing and let them have strong design thinking and a broad vision.

In the teaching of Chinese painting major, color teaching also occupies quite an important position. The courses offered by Prof. Han Jingwei of Chinese painting department mainly cover aspects of layout, relationship and color composition etc. The emphasis and difficulty in his course is how to train traditional Chinese painting major students' perception toward color. The majority of people agree Chinese paintings requires less sensitivity toward color and students of Chinese painting major cannot be blamed for having a plain sensitivity for colors, which in fact is a myth as in "Table I" and "Table II".

4 Freshman's Credit of Optional Course 6 Credits (Exclusive in Historical Comments).

TABLE I. ELECTIVE COURSES OF UNDERGRADUATE TRAINING PROGRAM OF CLASSES OF 2017

\begin{tabular}{|l|l|l|}
\hline 00804723 & Pattern & 3 Credits \\
\hline 00804733 & Calligraphy & 3 Credits \\
\hline 00804753 & Sketch & 3 Credits \\
\hline 00804763 & $\begin{array}{l}\text { Flower and Bird (Fine } \\
\text { Brushwork) }\end{array}$ & 3 Credits \\
\hline 00804783 & Photography & 3 Credits \\
\hline 00804773 & Structure & 3 Credits \\
\hline 00803233 & Sketching Drawing & 3 Credits \\
\hline 00803243 & Color Sketch & 3 Credits \\
\hline 00804803 & Anatomy for the Artist & 3 Credits \\
\hline 00804743 & Line Sketch & 3 Credits \\
\hline 00804683 & $\begin{array}{l}\text { Enjoyable Flower and } \\
\text { Bird Painting }\end{array}$ & 3 Credits \\
\hline
\end{tabular}

Courses apply the results of the experiment based on chromatology theory and point out the matters that color contrast and conversion of changes in temperature, and the color reveals different connotations in diverse temperature system. This discloses the key to the understanding of contemporary ink painting and color collocation, which is the entry of color leads the original kind of painting to produce the corresponding cold and warm change, which tendency is exeactly controlled by color. It is also an important embodiment of the color culture in the overall cultivation of Chinese painters. Through the training of jutaposition of color blocks, the students can understand color is not equal to color perceptions. What really bring people a wonderful visual feeling is not a simple color, but a unified system of color change. Painters' color perceptions can only be gradually established through a long-erm and conscious training, and by the process of building their aesthetic habits. Students being trained in observing nature and appreciate the paintings, they should rationally summarize different color changes in the environment during the process, and then they get a clear image of how the visual reaction functions in the process of mixing, how color show its dimensional feeling itself, and its texture and a series of reactions caused by it. Students are supposed to use these series of essential factors of color freely in the process of painting in order to improve the quality of the color and eventually achieve the stage of using color to convey and guide visual or psychological feelings.

"The most difficult part of painting is to draw dark colors. Once a dark color being mistakenly applied, the whole painting would be destroyed, while light colors are relatively easy." 2 Referred Sun Kuang Trailer Passgae of Shitian Drawing Volumn in of Chinese Ming Dynasty. The experience of the painter is essentially the feeling of purity and lightness in the three elements of color.

TABLE II. COMPULSORY COURSES OF THE UNDERGRADUATE TRAINING PROGRAM OF THE Class OF 2017

\begin{tabular}{|c|c|c|}
\hline Chinese Paintings & & $\begin{array}{c}49 \\
\text { Credits }\end{array}$ \\
\hline 30806833 & Linearity Sketch & 3 Credits \\
\hline 00000000 & Portrait Facsimileing & 3 Credits \\
\hline 00000000 & $\begin{array}{l}\text { Basic Skill of Brush and Ink } \\
\text { (Landscape Techniques) }\end{array}$ & 3 Credits \\
\hline 40808522 & Composition Practice & 2 Credits \\
\hline 30803162 & Creation Practice (1) & $\begin{array}{c}2 \\
\text { Credits } \\
\end{array}$ \\
\hline 30806843 & $\begin{array}{l}\text { Morphologic Expression of } \\
\text { Chinese Painting }\end{array}$ & 3 Credits \\
\hline 00000000 & $\begin{array}{l}\text { Basic Skill of Brush and Ink } \\
\text { (Flower and Bird Techniques) }\end{array}$ & 3 Credits \\
\hline 00000000 & Portrait Facsimileing Sketch & 3 Credits \\
\hline 00000000 & Classical Landscape Facsimileing & 3 Credits \\
\hline 30803273 & $\begin{array}{l}\text { Classical Portrait Facsimileing } \\
\text { (Fine Brushwork) }\end{array}$ & 3 Credits \\
\hline 30806753 & Portrait Sketch (Ink and Wash) & 3 Credits \\
\hline 00000000 & Landscape Sketch & 2 Credits \\
\hline 40800692 & Creation Practice (2) & 2 Credits \\
\hline 00000000 & $\begin{array}{l}\text { Classical Enjoyable Flower and } \\
\text { Bird Painting Facsimileing }\end{array}$ & 2 Credits \\
\hline 00000000 & $\begin{array}{l}\text { Classical Flower and Bird Painting } \\
\text { Facsimileing } \\
\text { (Fine Brushwork) }\end{array}$ & 3 Credits \\
\hline 00000000 & $\begin{array}{l}\text { Tinted Portrait Sketch in Fine } \\
\text { Brushwork }\end{array}$ & 3 Credits \\
\hline 40809562 & Experimental Ink and Wash & 2 Credits \\
\hline 00000000 & $\begin{array}{cc}\text { Topic Selection and } \\
\text { Completion of Thesis }\end{array}$ & 1 Credits \\
\hline
\end{tabular}

Liang XiaoYi of the Southern Dynasties put forward in Landscape of Pine Tree and Stones of the concept "fervent red and chilly blue", "warm sun and cool star". 3This is the first time in Chinese painting history that concept of visual peception for cool and warm colors is being proposed. Although he did not use the term cool or warm color, he expressed the same kind of color perception with the western concept.

Painter summed up the appropriate temperature difference between colors from their long-term observing experiences, so they can determine what kind of color is harmonious with their sharp eyes. Even the complementary color is hard to be coordinated at the beginning, the painter can establish an effective connection through one or a few colors, and they enable all the colors achieve the unity of

\footnotetext{
2 An Abstract of Chinese Painting Theory, Zhou Jiyan, Jiangsu Arts Press. Page 516 of the 1933 edition.

3 Landscape of Pine Tree and Stones, Liang Xiaoyi of the Southern Dynasties. Page 510.
} 
opposites in a reasonable range. This is the ultimate goal of training for color perception, which is whether to depict a particular object or some kind of mood a painter can guarantee the quality of color and make the picture be full of lights.

Mr. Du Dakai's work is one of the representatives for the teaching ideas of Tsinghua Academy of Arts. Mr. Du starts to paint with western style color expression, and he bases on the inherent color and seeks for changes in temperature and coordination between color pieces. As for the paint of colors, he still uses traditional Chinese way of painting technique to cover flat and coat dyeing the picture, and he applies flat and concise color piece to form his work with both oriental flavor and colour feeling. Chinese painting is distinctive from the western landscape painting in color reappearance technique. Chinese painting do not pursue the accuracy of the size and the space using light and shadow, but it portrays the contrast and unity between the land and vegetation through a kind of the spirit of freehand brushwork. With different techniques of using the ink, painters bring unique aesthetic experience of Chinese painting, showing colors with method of plane composition to enrich shapes of the contents on the basis of the ink draft. The coordinated color blocks are shaded according to the situation of natural objects and the size of the area, and finally paintets form the shape and spirit of colors.

\section{CONCLUSION}

From the macroscopic view to assess the development of the culture and art, the development of any genre of civilization is not completely isolated. During the evolvement, the art itself involves the potential of innovation, which will generate new sparkles spurred by other external factors. Every traditional culture was once a new trend when it was born. Facing the impact from western arts, Chinese painters began to be suspicious of the previous Chinese paintings at the very beginning of reforming, and then the painters showed a radical attitude towards the new influence. As they gradually adapted themselves to the color and they could apply the colors efficiently, they gradually shifted the national inner expression into outer appearance. Thus, the color becomes the important factor in painting since 20th century. In 20th century, Chinese painting circle basically reached a consensus on future's orientation: based on the essence of traditional Chinese culture, drawing on all elite culture available, the Chinese painting would have a more broadened horizon.

Central Academy of Craft Art, absorbing the traditional culture, drawing lessons from international teaching system, was the first college to start China's design teaching. After being a part of Tsinghua University, the Academy retains its teaching method, develops the pedagogy and gradually becomes one of the best design schools in China. Since the establishment of the Academy of Arts \& Design of Tsinghua University is a bit late, influenced by the Central Academy of Craft Art, the teaching method in drawing major continues the tradition of decoration-and-pattern orientation as well. The cultivation in terms of the color is paid much attention in the Academy of Arts \& Design of Tsinghua University, which is clearly distinguished among the Chinese general teaching systems focusing on brush and ink work. When the teachers educate students, they could teach students in accordance of their aptitudes. They could develop young students with both inclusive and creative perspectives from the point of macro aesthetics. For it's a little late for the Chinese painting to become a major and the major covers a variation of fields, there must be, to a certain extent, some insufficient in terms of the discipline's profession. The fault is also in its counterparts, so it is an urgent issue for the Chinese painting Department in the Academy of Arts \& Design of Tsinghua University to tackle with.

\section{REFERENCES}

[1] Yu Jianhua. "Classification of Chinese Painting Editorial", Beijing: People's Fine Arts Publishing House, 1986 edition

[2] A Brief History of Academy of Arts and Design of Tsinghua University, chiefly edited by Hang Jian, edited by of academy history compilation group, Tsinghua University Press, 2011 edition

[3] Zhou Jiyin. "Summary of Chinese Painting Editorial", Jiangsu: Jiangsu Fine Arts Publishing House, 1993

[4] (UK)Michael Sullivan, Chinese Art and Artists in the 20th Century, translated by Chen Weihe \& Qian Gangnan, Shanghai: Shanghai People's Publishing House, 2013

[5] (Qing) Wang Yuanqi. Rain Window Manuscript, Hangzhou: Xiling Yinshe Publishing House, 2008 